\title{
ZS Research Square

\section{Application of a 2D hydrodynamic model for the assessment of the influencing factor in Xiangxi Bay of the Three Gorges Reservoir}

RANOJIT KUMAR DUTTA ( $\square$ ranojit.dutta83@gmail.com )

China Three Gorges University

\section{Baishakhi Das}

Bangladesh National University

\section{Research Article}

Keywords: Algal blooms, Xiangxi Bay (XXB), CE-QUAL-W2 model, Density currents, Three Gorges Reservoir (TGR)

Posted Date: February 9th, 2021

DOI: https://doi.org/10.21203/rs.3.rs-198769/v1

License: (c) (i) This work is licensed under a Creative Commons Attribution 4.0 International License.

Read Full License 


\title{
Application of a 2D hydrodynamic model for the assessment of the influencing factor in Xiangxi Bay of the Three Gorges Reservoir
}

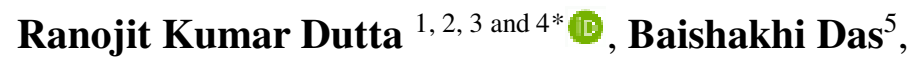 \\ 1 College of Hydraulic and Environmental Engineering, China Three Gorges University, \\ Yichang, 443002, Hubei, P.R.China. \\ 2 School of Civil Engineering, Architecture and Environment, Hubei University of \\ Technology, Wuchang, Wuhan, 430068, Hubei, P. R. China \\ 3 Faculty of Engineering, Bangladesh University of Engineering and Technology (BUET), \\ Dhaka 1000, Bangladesh. \\ 4 Faculty of Science and Engineering, GED, City University, Dhaka 1216, Bangladesh \\ 5 International Relations, Department of Political Science, NU, Dhaka, Bangladesh \\ *Corresponding author E-mail: ranojit.dutta83@gmail.com (Dr. Dutta)
}

\begin{abstract}
:
A two-dimensional (2D), laterally averaged, hydrodynamic and water quality model, CEQUAL-W2, was used to simulate the hydrodynamics and water temperatures of Xiangxi Bay (XXB) of the Three Gorges Reservoir (TGR). Algal blooms occurred seasonally in $\mathrm{XXB}$ which is influenced by density currents. The CE-QUAL-W2 model was calibrated using data collected in XXB from January to December 2010. The model was then used to examine the environmental factors that affect the density currents. The model predicted density currents such as overflows, interflows and underflows of the XXB. The results suggest that more than $25 \%, 58.33 \%$ and $16.67 \%$ of the density currents that occurred in the XXB were overflow, interflow and underflow, respectively. Field observations were conducted including travel distance and thickness of intrusion layer for 24 days in 2010. The average travel distance of overflow, interflow and underflow in XXB was $15.50 \mathrm{~km}$, $8.78 \mathrm{~km}$, and $9 \mathrm{~km}$ based on observations and $16 \mathrm{~km}, 9.40 \mathrm{~km}, 9.60 \mathrm{~km}$ based on the model results. Therefore, numerical simulations of density currents can be predicted to better understand the hydrodynamics and aquatic ecosystems in XXB of TGR.
\end{abstract}


Keywords: Algal blooms; Xiangxi Bay (XXB); CE-QUAL-W2 model; Density currents; Three Gorges Reservoir (TGR)

$\begin{array}{ll} & \text { List of abbreviations } \\ \text { XXB } & \text { Xiangxi Bay } \\ \text { TGR } & \text { Three Gorges Reservoir } \\ \text { TGD } & \text { Three Gorges Dam } \\ \text { YR } & \text { Yangtze River } \\ \text { CTGC } & \text { China Three Gorges Corporation } \\ \text { AME } & \text { Absolute Mean Error } \\ \text { RMSE } & \text { Root Mean Square Error } \\ \text { [I] } & \text { Segment } \\ \text { [K] } & \text { Layer number } \\ \text { (K, I) } & \text { Cell } \\ \text { JD } & \text { Julian Day } \\ \text { TGP } & \text { Three Gorges Project } \\ \text { WSE } & \text { Water surface elevation } \\ \text { Sim } & \text { Simulated } \\ \text { Obs } & \text { Observed } \\ \text { Mod } & \text { Modeled }\end{array}$




\section{Introduction}

The Three Gorges Reservoir (TGR) is located at the end of the upper Yangtze River (YR) in central China. It has many tributaries, including Xiangxi Bay (XXB), which is the largest tributary in the lower reach of the TGR and $32 \mathrm{~km}$ from Three Gorges Dam (Figure. 1a). The Three Gorges Project (TGP) has created substantial social and economic benefits, such as power generation, flood control, river navigation, drought prevention and freshwater impoundment in central China $[1,2,3,4]$. However, the aquatic environment of the area has significantly changed since impoundment (2003) [1, 2, 3, 5]. Algal blooms have occurred frequently in many tributaries, including $\mathrm{XXB}[1,2,3]$. Density currents influence algal blooms because these currents transport nutrients and trace elements $[1,3$, 7, 13]. Additionally, density currents are influenced by the thermal stratification of the reservoir $[2,8,9,10,15]$. Analyses of long-term data records suggest that algal blooms in the tributaries of TGR are sensitive to changes in thermal stratification, hydrodynamics and nutrient loads [1, 4, 7]. Based on long-term field observations, Ji et al. (2010) noted that density currents occur frequently in XXB. Je et al. (2010) also noted that the water in the TGR mainstream flowed backward into XXB at different plunging depths due to the water temperature differences between the TGR mainstream and XXB. Density currents are also affected by upstream inflows into XXB and intrusion flows from the TGR mainstream and these currents affect the algal blooms and aquatic ecosystems in XXB [1, 2, 3, 4]. Density currents exist below the ambient water level and form different flows, such as overflows, interflows and underflows $[8,11,12]$. Numerous studies have investigated density currents around the world, including research on density currents $[6,10,11,12]$. Numerical models 
have become widely accepted tools for predicting and diagnosing hydrodynamic problems $[17,18,19,20,21]$

The objective of this paper is to investigate density currents in XXB of the TGR using a two-dimensional, laterally averaged, hydrodynamic model based on CE-QUALW2. This paper focus on the characteristics of density currents, such as overflows, interflows, underflows, the thickness of the intrusion layer, plunge point locations and the travel distance of the density currents in XXB.
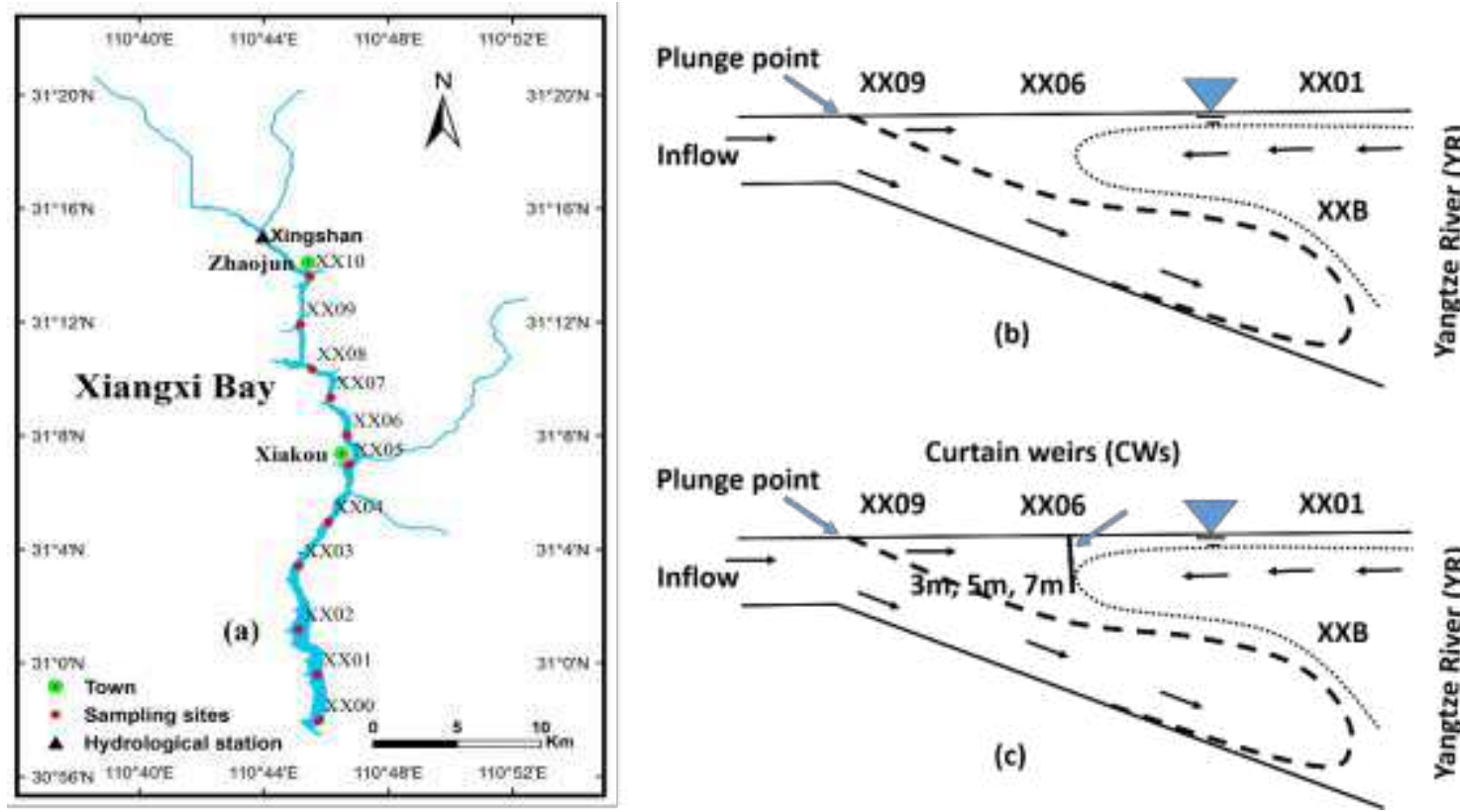

Figure. 1 (a) Location of the sampling sites in the XXB, (b) Schematic representation of density currents at XXB, (c) Curtain weirs (CWs) illustrates the block density currents.

\section{Materials and methods}

\subsection{Study area}

$\mathrm{XXB}$ is located (from $110^{\circ} 25^{\prime} \mathrm{E}$ to $111^{\circ} 06^{\prime \prime} \mathrm{E}$ and from $30^{\circ} 57^{\prime} \mathrm{N}$ to $31^{\circ} 34^{\prime} \mathrm{N}$ ) in Hubei Province, China. The bay has a watershed area of $3095 \mathrm{~km}^{2}$ and an annual average flow of $47.4 \mathrm{~m}^{3} / \mathrm{s}[1,2,3,4]$. Eleven field stations were considered for the model developed 
from upstream to downstream. The sampling points were XX09, XX06 and XX01, corresponding to computational grid sections 9, 25 and 58, respectively (Figure. 1b). A computational grid of XXB was developed based on the bathymetric and geometric data. The XXB was represented by 64 longitudinal segments, each $500 \mathrm{~m}$ in length, and 109 vertical layers, each $1 \mathrm{~m}$ thick [1, 4]. CE-QUAL-W2 has several coefficients that can be adjusted in the calibration process $[17,18,19,20,21]$. Model performance was evaluated by the absolute mean error (AME) and the root mean square error (RMSE) statistics.

\section{Results}

\subsection{The effects of density currents on overflow in XXB}

Overflow intrusion density currents occurred in XXB on March 23, April 20, May 30, June 14, November 01 and December 15, 2010 according to field monitoring. Approximately $25 \%$ of the density currents that occurred in XXB in 2010 were overflow density currents according to the observation data. Density currents can enter the surface layer based on the magnitude of this density difference. The average travel distance of overflow in XXB was $15.50 \mathrm{~km}$ based on observations and $16 \mathrm{~km}$ based on the model results (Table 1). In the early spring, the water density of $\mathrm{XXB}$ gradually decreased and thermal stratification occurred. Overflow density currents enter from the mainstream to XXB in a clockwise direction, as shown in Figure. 3 (a) and Figure 3 (b). In mid-spring, the temperature gradually increases and thermal stratification pattern should reverse to the anti-clockwise direction as shown in Figure. 3 (c). In the late spring, the temperature should be uniform but upstream inflow will be colder than surface waters, as shown in Figure. 3 (d). 

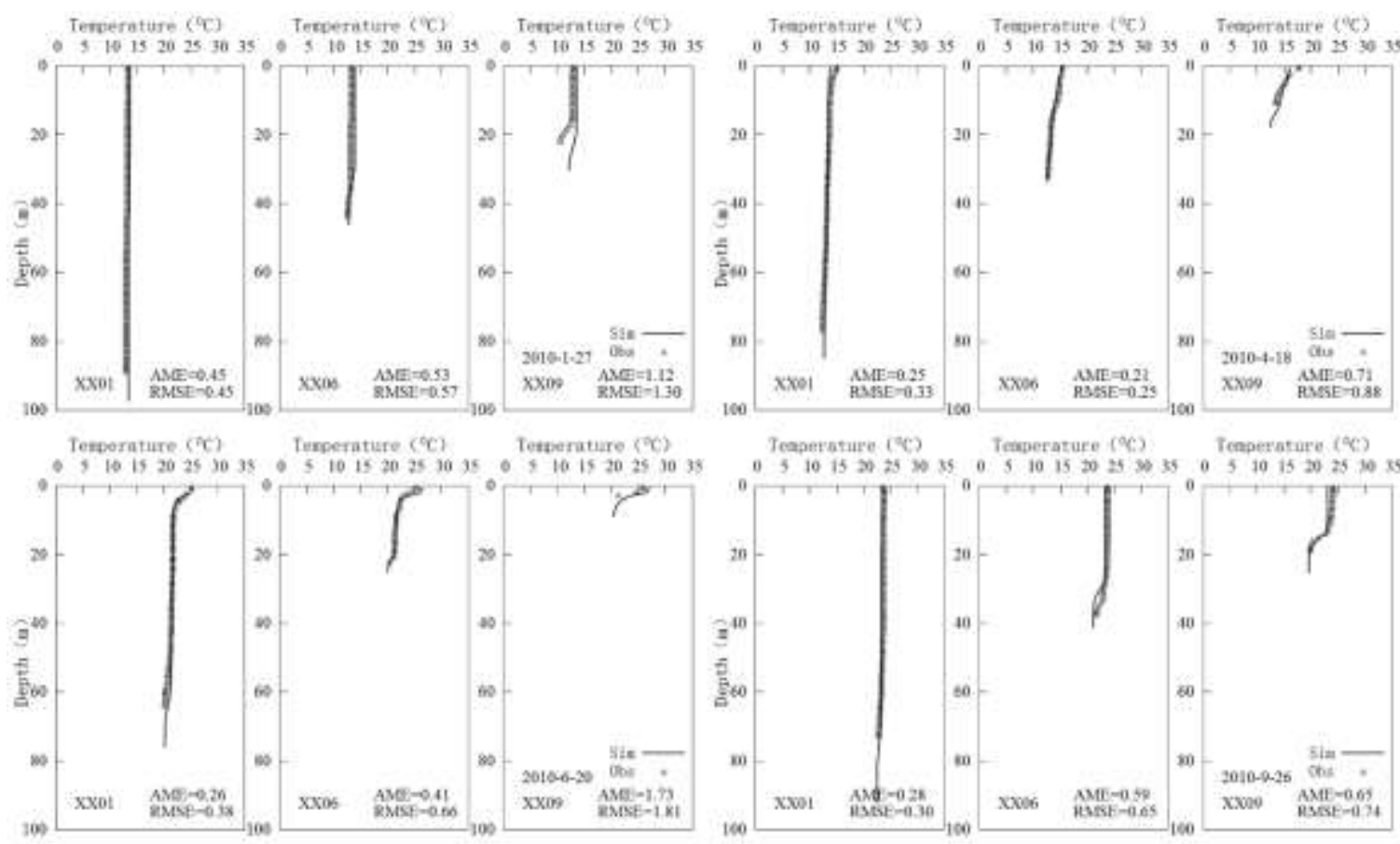

Figure. 2 Temperature profile simulated (Sim) and observed (Obs) for XXB

When overflow intruded to the XXB from the mainstream simultaneously inflow occurred underflow from the upstream while algal blooms underneath gradually as shown in Figure. 3. 


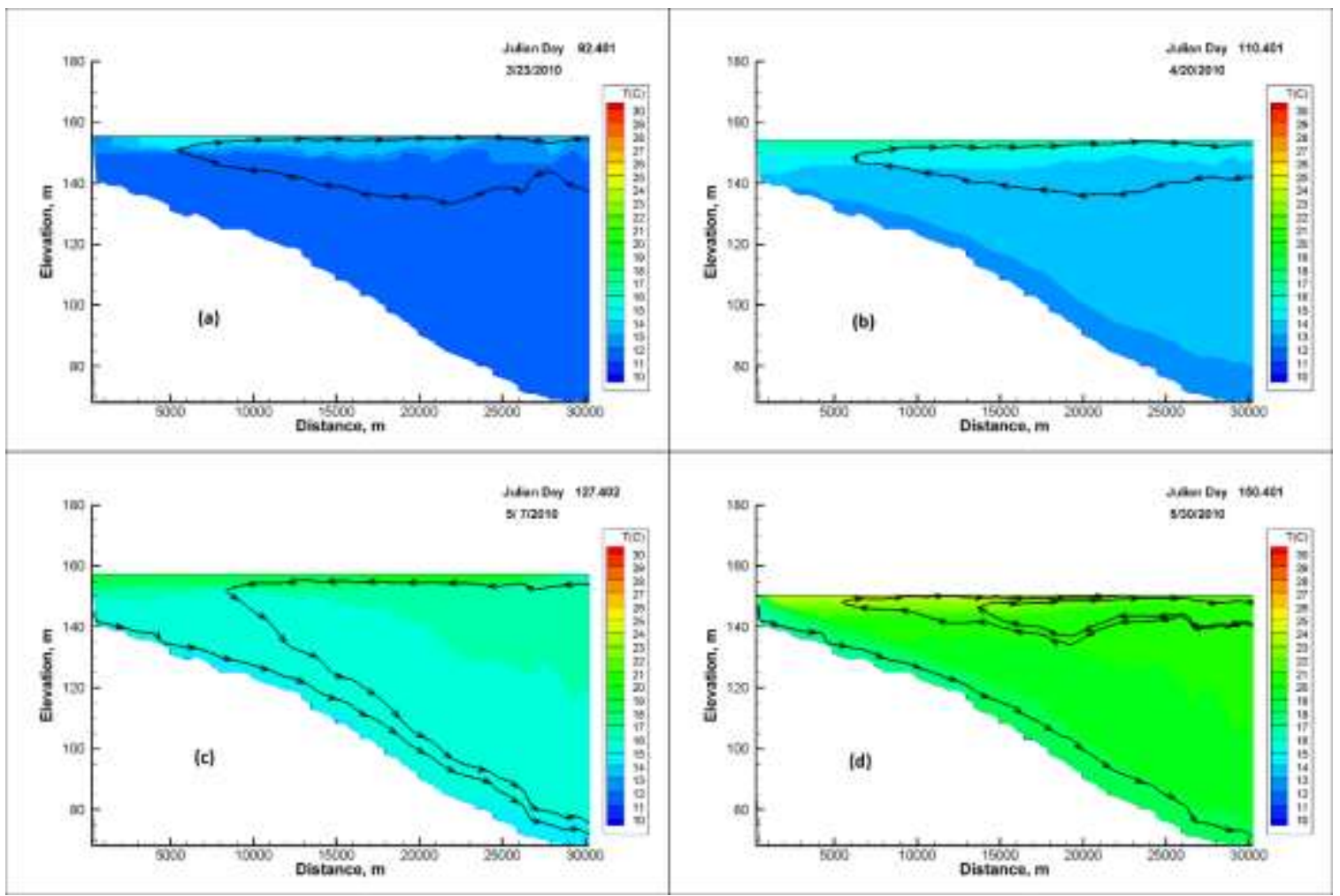

Figure. 3 Contour plots represent overflow for XXB

\subsection{Density current effects as an interflow in XXB}

Interflow density currents occurred in XXB of the TGR on January 1, February 16, March 2, April 10 and 26, June 9, July 9 and 30, August 25, September 3 and 20, October 5 and 27 and November 30, 2010 according to field monitoring. Approximately 58.33\% of the density currents that occurred in XXB in 2010 were interflow density currents. The average travel distance of interflow in XXB was $8.78 \mathrm{~km}$ based on observations and $9.40 \mathrm{~km}$ based on the model results (Table 1). In summer, the water temperature increased significantly and the density was very low in XXB. Interflow patterns reversed to an anti-clockwise direction on June 9, July 30 and August 25 but not on August 1 as shown in Figure. 4 (e), (f), (g) and (h). Interflow density currents entered from the mainstream to XXB in a clockwise direction when the temperature gradually increased in summer, as shown in 
Figure. 4 (e), (f) and (h). The upper surface layer temperature should be higher than that of the middle layer as a result of the outbreak of algal blooms in the upper surface in XXB.

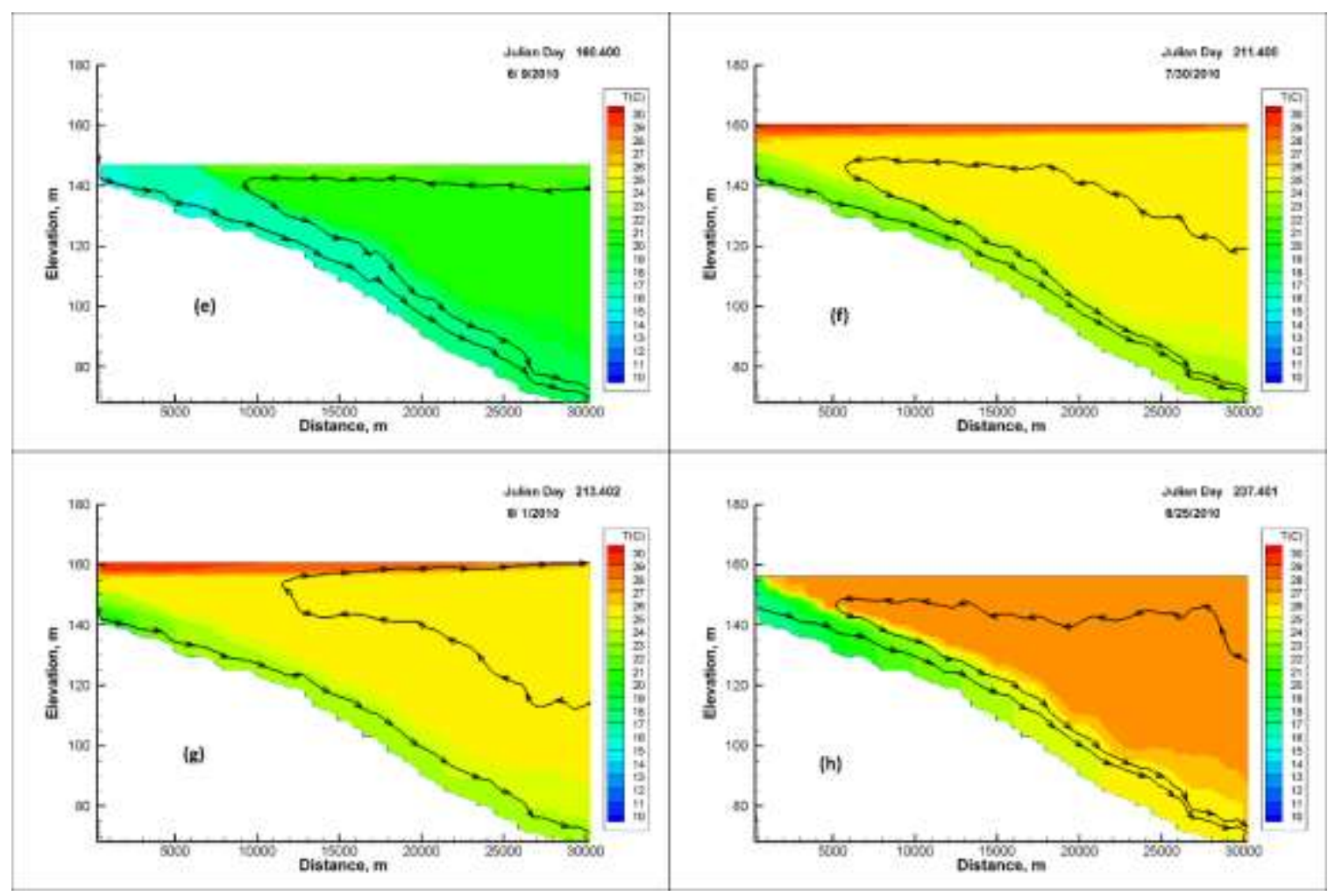

Figure. 4 Contour plots represent interflow for XXB

\subsection{Density current effects as an underflow in XXB}

Underflow intrusion density currents occurred on May 10, June 4, August 28 and December 20, 2010 according to field observation. Approximately $16.67 \%$ of the density currents that occurred in XXB in 2010 were underflow density currents (Table 1). In XXB, underflow density currents occurred in the late summer and autumn when tributaries were still warm as shows in Figure. 5. The average travel distance of underflow in XXB was 9 $\mathrm{km}$ based on observations and $9.60 \mathrm{~km}$ based on the model results. At the end of summer, the water temperature decreased significantly and the water density increased gradually in XXB. Underflow circulation patterns changed to an anti-clockwise direction on August 28 
and October 18, as shown in Figure. 5 (i) and (j). Underflow density currents entered from the mainstream to XXB in a clockwise direction when the temperature gradually increased in summer and in an anti-clockwise direction in winter, except on February 28, as shown in Figure. 5(k) and (1). When underflow intruded into XXB from the mainstream, inflow simultaneously entered from the upstream of XXB while density-stratified layers were formed as shown Figure. 5 (i), (j), (k) and (l). Algal blooms outbreaks occurred on the upper surface layer in summer due to the density currents in XXB.

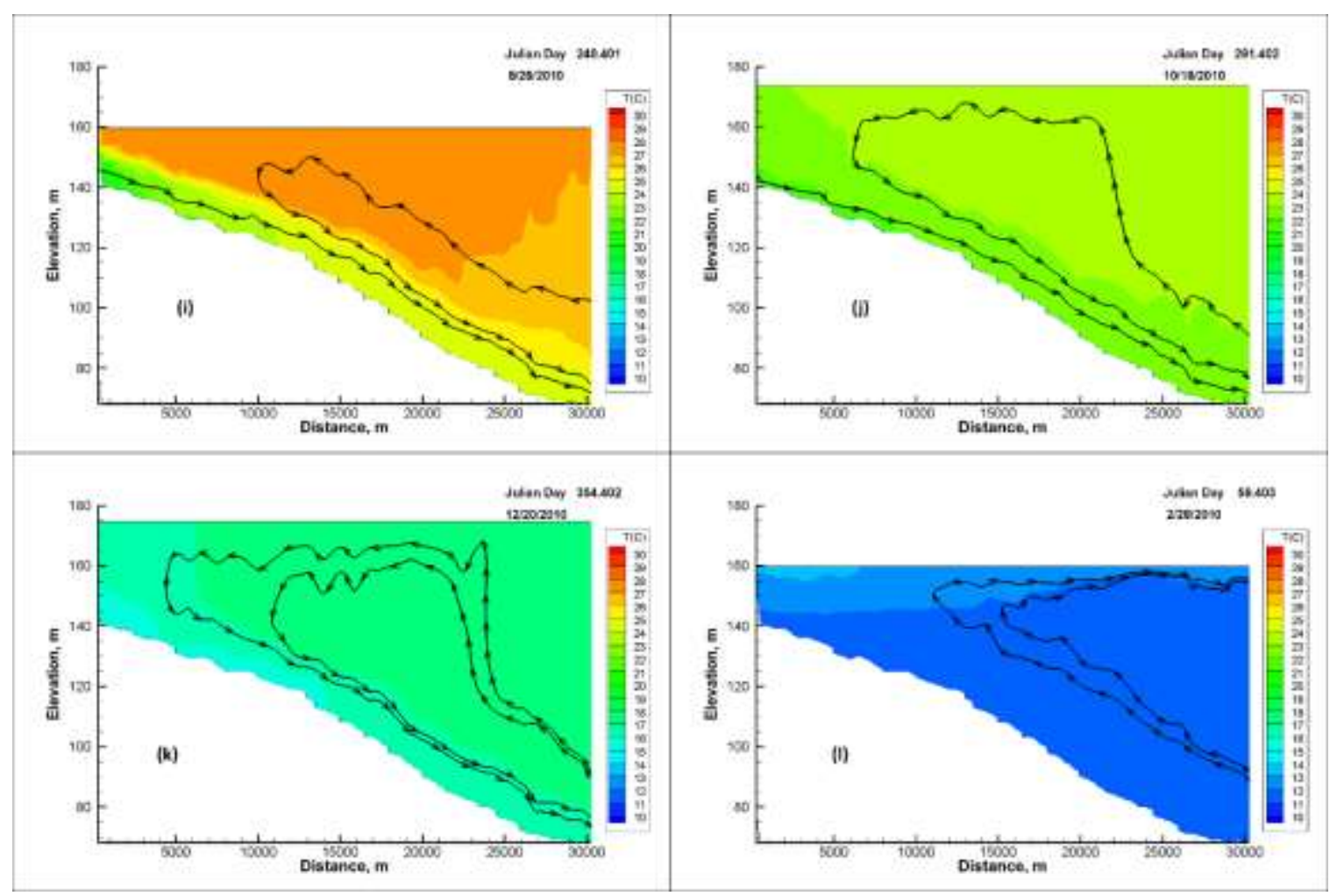

Figure. 5 Contour plots represent underflow for XXB 
Table 1 Density currents analysis for XXB

\begin{tabular}{lllllll}
\hline $\begin{array}{l}\text { Density } \\
\text { currents }\end{array}$ & $\begin{array}{l}\text { Field } \\
\text { observation } \\
\text { 24 days }\end{array}$ & $\begin{array}{l}\text { Travel distance }(\mathrm{km}) \\
\text { average }\end{array}$ & $\begin{array}{l}\text { Thickness of the } \\
\text { intrusion } \\
(\mathrm{m}) \\
\text { layer }\end{array}$ & $\begin{array}{l}\text { Density } \\
\text { current } \\
\text { occurred } \\
(\%)\end{array}$ \\
\hline & & & & & \\
& & & & & \\
\hline Overflow & 6 & Obs. & ${ }^{* *}$ Mod. & ${ }^{*}$ Obs. & ${ }^{* *}$ Mod & \\
Interflow & 14 & 15.50 & 16 & 25.83 & 25.70 & 25 \\
Underflow & 4 & 8.78 & 9.40 & 47.78 & 48.42 & 58.33 \\
\hline
\end{tabular}

${ }^{*}$ Obs. $=$ Observed

***Mod. = Modeled

\section{Discussion}

\subsection{Density current effects on thermal stratification in $X X B$}

Thermal stratification is influenced by the density currents in XXB. The upstream reaches exhibited much stronger stratification than those downstream $[1,2,3,4]$. In XXB, the CEQUAL-W2 model effectively captures the seasonal changes in water temperature and stratification in the reservoir $[1,4,7,18]$. The difference between observed and simulated temperature is generally below $4^{\circ} \mathrm{C}$ in $\mathrm{XXB}$. The thermocline depth is accurately simulated during the simulation period. The model performance was evaluated according to the absolute mean error (AME) and the root mean square error (RMSE) values. The upstream AME was $1.12^{\circ} \mathrm{C}, 0.71^{\circ} \mathrm{C}, 1.73^{\circ} \mathrm{C}$ and $0.65^{\circ} \mathrm{C}$ and the RMSE was $1.30^{\circ} \mathrm{C}, 0.88^{\circ} \mathrm{C}, 1.81^{\circ} \mathrm{C}$ and $0.74^{\circ} \mathrm{C}$ at XX09 on January 27, April 4, June 6 and September 26 in 2010 respectively (Figure. 2). The midstream XX06 AME was $0.53{ }^{\circ} \mathrm{C}, 0.21^{\circ} \mathrm{C}, 0.41^{\circ} \mathrm{C}$ and $0.59^{\circ} \mathrm{C}$ and the RMSE was $0.57^{\circ} \mathrm{C}, 0.25^{\circ} \mathrm{C}, 0.66^{\circ} \mathrm{C}$ and $0.65^{\circ} \mathrm{C}$ on these same dates, respectively (Figure. 2). The downstream $\mathrm{XX01} \mathrm{AME}$ was $0.45^{\circ} \mathrm{C}, 0.25^{\circ} \mathrm{C}, 0.26^{\circ} \mathrm{C}$ and $0.28^{\circ} \mathrm{C}$ and the RMSE 
$0.45^{\circ} \mathrm{C}, 0.33^{\circ} \mathrm{C}, 0.38^{\circ} \mathrm{C}$ and $0.30^{\circ} \mathrm{C}$ on these dates, respectively (Figure. 2). There was no thermocline on January 18, February 16 or March 22, 2010 at site XX01, as shown in Figure. 3. However, on June 2 and 19, and July 5 and 20, 2009, weak stratification existed, as shown in Figure. 4. As shown in Figure. 4 (f), (g) and (h), a strong thermal stratification was formed on August 2 and August 17, 2010. In the middle reaches of XXB, the thermal stratification was disrupted by the intrusion from the TGR mainstream via the middle layer at the XXB mouth. At site XX06, on January 18 and February 16, the layers were well mixed, but on March 29, April 20 and May 23, 2010, a thermocline was present, as shown in Figure. 4 (f), (g) and (h). As shown in Figure. 5 (i) and (j), site XX06 exhibited strong thermal stratification on July 5 and 19, and August 2 and 17 and September 20 and 21, 2010. On the above dates, the thermal stratification was medium at site XX09 in XXB, as shown in Figure. 4 (e) and Figure. 5 (k).

\subsection{Density current control technique for $X X B$}

Though Xinagxi Bay of the TGR is located in a subtropical continental monsoon climate area algal blooms occurred seasonally $[1,2,3]$. Upstream inflow is separated into two types: over the surface as overflow and on the bottom as underflow. After installation the curtain weir inflow propagation path will be interrupted as shown in Figure. 1(c). Inflow exhibited plunge flow before the curtain weir location and later travel as interflow under curtain with different heights such as $3 \mathrm{~m}, 5 \mathrm{~m}$ and $7 \mathrm{~m}$ below the water surface $[4,7,14$, $15,18]$. The dilution rate of the surface layer increases with the curtain weir height and enhanced the submergence interflow $[4,7,13,14,16,17,19,20,21]$. The submergence level of interflow should be interrupted because the curtain weirs have different heights and locations including upstream, midstream and downstream, corresponding to XX09, 
XX06 and XX01, respectively Figure. 1(c). We assumed that after installation the curtain weir density current would be interrupted and would, in turn, alter the thermal stratification in XXB (Figure. 1c). Overflow, interflow and underflow should be interrupted and control algal blooms due to the effect of curtain weirs applied at different reservoirs $[4,7,15,16$, 18]. Our further research will be on modeling curtain weirs and its effects on controlling algal blooms in a subtropical reservoir of China.

\section{Conclusions}

Density currents provide important information regarding transport dynamics and stratified flows. These currents are the main environmental factors that affect XXB. The CE-QUALW2 model performed well in simulating the unusual thermal stratification, overflows, interflows, underflows, travel distances, and thicknesses of the intrusion layers in XXB. The model predicted that, more than $25 \%, 58.33 \%$ and $16.67 \%$ of density currents in XXB were overflows, interflows and underflows, respectively. The average travel distance of overflow, interflow and underflow in XXB was $15.50 \mathrm{~km}, 8.78 \mathrm{~km}$, and $9 \mathrm{~km}$ based on observations and $16 \mathrm{~km}, 9.40 \mathrm{~km}, 9.60 \mathrm{~km}$ based on the model results. The model theoretically confirmed the long-term existence of density currents and indicated that density currents have a major hydrodynamic influence in XXB. Density currents carry nutrients, solids and other substances that affect reservoir water quality. These materials may enter XXB through overflow, interflow and underflow from the mainstream. Curtain weir numerical simulations should be performed to control density currents in XXB. Additionally, due to the application of curtain weirs algal blooms should be controlled in $\mathrm{XXB}$ of the TGR. 


\section{Funding}

This research received no external funding.

\section{Acknowledgments}

The author is grateful to all of the members of the Hubei Key Laboratory of Ecological Restoration of River-lakes and Algal Utilization, Hubei University of Technology, Wuhan and China Three Gorges University, Yichang for participating in the field monitoring.

\section{Conflicts of Interest}

The authors declare no conflict of interest.

\section{References}

1. Ma, J.; Liu, D.; Wells, S.A.; Tang, H.; Ji, D.; Yang, Z. Modeling density currents in a typical tributary of the Three Gorges Reservoir, China. Ecological Modelling 2015, 296, 113-125, doi:https://doi.org/10.1016/j.ecolmodel.2014.10.030

2. Yang, Z.; Liu, D.; Ji, D.; Xiao, S.; Huang, Y.; Ma, J. An eco-environmental friendly operation: An effective method to mitigate the harmful blooms in the tributary bays of Three Gorges Reservoir. Science China Technological Sciences 2009, 56, 1458-1470, doi:10.1007/s11431-013-5190-9.

3. Ji, D.; Wells, S.A.; Yang, Z.; Liu, D.; Huang, Y.; Ma, J.; Berger, C.J. Impacts of water level rise on algal bloom prevention in the tributary of Three Gorges Reservoir, China. Ecological Engineering 2017, 98, 70-81, doi:https://doi.org/10.1016/j.ecoleng.2016.10.019.

4. Dutta, R.K.; Ma, J.; Das, B.; Liu, D. Modeling Effects of Floating Curtain Weirs and Controlling Algal Blooms in a Subtropical Reservoir of China. American Journal of Water Resources 2019, 7, 42-49. DOI: 10.12691/ajwr-7-2-1

5. Yang Z J, L.D.F., Ji D B, Influence of the impounding process of the Three Gorges Reservoir up to water level $172.5 \mathrm{~m}$ on water eutrophication in the Xiangxi Bay. Science China Technological Sciences, 2010. 53: p. 1114-1125. https://doi.org/10.1007/s11431-0090387-7

6. Benjamin, T.B., Gravity currents and related phenomena. Journal of Fluid Mechanics, 1968. 31( 2 ): p. 209-248. https://doi.org/10.1017/S0022112068000133

7. Dutta, R.K.; Ma, J.; Das, B.; Liu, D. Modeling Effects of Bottom Curtain Weirs and Controlling Algal Blooms in Xiangxi Bay, Three Gorges Reservoir, China. American Journal of Water Resources 2019, 7, 50-57.

8. Dingguo, J., D. Huichao, and L. Wei, Influence of Thermal Density Flow on Hydrodynamics of Xiangxi Bay in Three Georges Reservoir, China. Procedia Environmental Sciences, 2011. 10: p. 1637-1645. doi: 10.1016/j.proenv.2011.09.258 
9. Zhang, X.-f., et al., Effect of thermal stratification on interflow travel time in stratified reservoir. Journal of Zhejiang University-SCIENCE A, 2016. 17(5): p. 416-416. https://doi.org/10.1631/jzus.A1400269

10. Akiyama, J., and Stefan, H. G., Theory of Plunging Flow into a Reservoir. ASCE, 1984. 110(4): p. 484-499. https://doi.org/10.1061/(ASCE)0733-9429(1984)110:4(484)

11. Alavian, V., Behavior of Density Currents on an Incline. Journal of Hydraulic Engineering, 1986. 112(1): p. 27-42. https://doi.org/10.1061/(ASCE)0733-9429(1986)112:1(27)

12. Elci, S., Effect of thermal stratification and mixing on reservoir water quality. Vol. 9. 2008. 135-142. https://doi.org/10.1007/s10201-008-0240-x

13. Bowen James, D. and W. Hieronymus Jeffrey, A CE-QUAL-W2 Model of Neuse Estuary for Total Maximum Daily Load Development. Journal of Water Resources Planning and Management, 2003. 129(4): p. 283-294. https://doi.org/10.1061/(ASCE)07339496(2003)129:4(283)

14. H. S. Lee, S.W.C., J. K. Choi \& B. H. Min, Feasibility of curtain weir installation for water quality management in Daecheong Reservoir. Desalination and Water Treatment 2010. 19: p. 164-172. https://doi.org/10.5004/dwt.2010.1883

15. Asaeda, T.; Priyantha, D.G.N.; Saitoh, S.; Gotoh, K. A new technique for controlling algal blooms in the withdrawal zone of reservoirs using vertical curtains. Ecological Engineering 1996, 7, 95-104, doi:https://doi.org/10.1016/0925-8574(96)00002-X.

16. Chung, S.W.L., H. Jung, Y., The effect of hydrodynamic flow regimes on the algal bloom in a monomictic reservoir. Water Sci Technol, 2008. 58(6): p. 1291-8. https://doi.org/10.2166/wst.2008.482

17. Lindenschmidt, KE., Carr, M.K., Sadeghian, A. et al. CE-QUAL-W2 model of dam outflow elevation impact on temperature, dissolved oxygen and nutrients in a reservoir. Sci Data 6, 312 (2019). https://doi.org/10.1038/s41597-019-0316-y

18. R.K. Dutta, B. Das, "Modeling curtain weirs for controlling algal blooms in the largest tributary of the Three Gorges Reservoir,China", Alexandria Eng. J. 2020, https://doi.org/10.1016/j.aej.2019.12.044

19. García-Feal, O.; Cea, L.; González-Cao, J.; Domínguez, J.M.; Gómez-Gesteira, M. IberWQ: A GPU Accelerated Tool for 2D Water Quality Modeling in Rivers and Estuaries. Water 2020, 12, 413. https://doi.org/10.3390/w12020413

20. Ryu, I.; Yu, S.; Chung, S. Characterizing Density Flow Regimes of Three Rivers with Different Physicochemical Properties in a Run-Of-The-River Reservoir. Water 2020, 12, 717. https://doi.org/10.3390/w12030717

21. Zamani, B.; Koch, M. Comparison Between Two Hydrodynamic Models in Simulating Physical Processes of a Reservoir with Complex Morphology: Maroon Reservoir. Water 2020, 12, 814. https://doi.org/10.3390/w12030814 
Figures
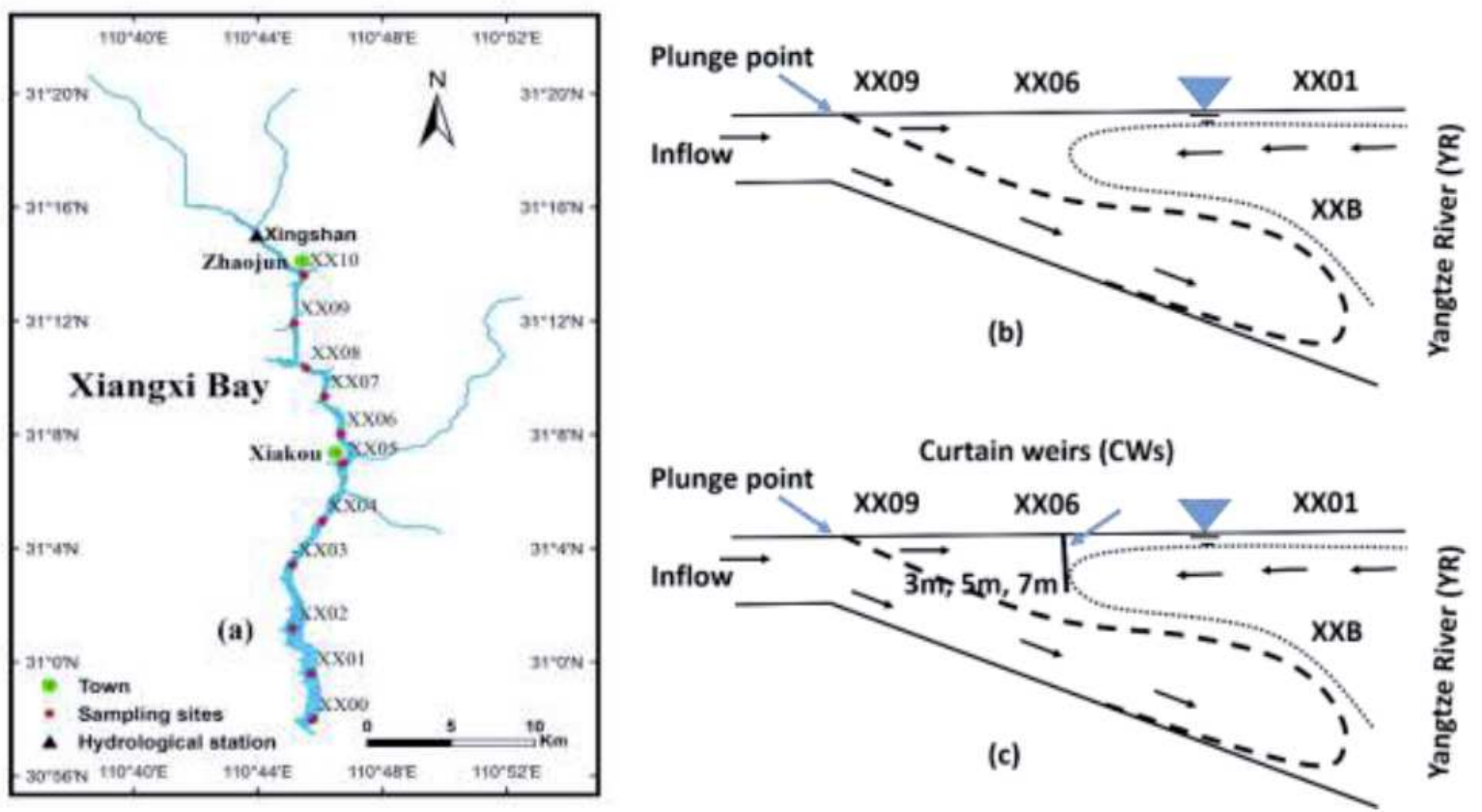

\section{Figure 1}

(a) Location of the sampling sites in the $X X B$, (b) Schematic representation of density currents at XXB, (c) Curtain weirs (CWs) illustrates the block density currents. Note: The designations employed and the presentation of the material on this map do not imply the expression of any opinion whatsoever on the part of Research Square concerning the legal status of any country, territory, city or area or of its authorities, or concerning the delimitation of its frontiers or boundaries. This map has been provided by the authors. 

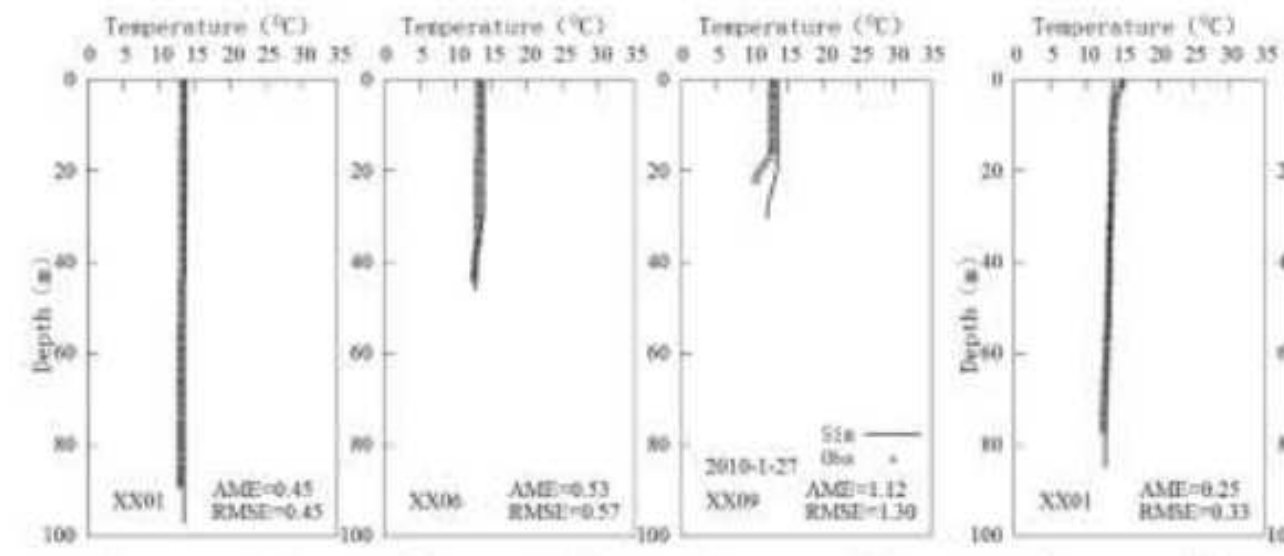

Temperatiare (for)

Trogerntare (qC)

Tescerature $(\mathrm{C})$ Tenoerature $\left({ }^{\circ} \mathrm{C}\right)$

Tesceruture $\left({ }^{\circ} \mathrm{C}\right\rangle$

Teapertature (\$)

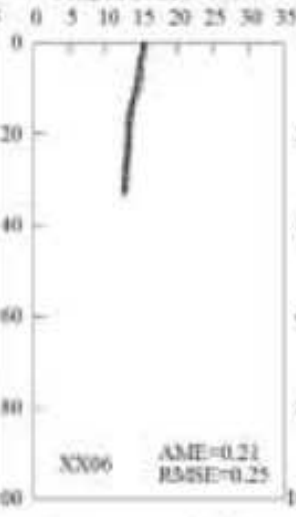

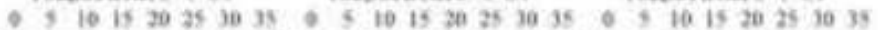
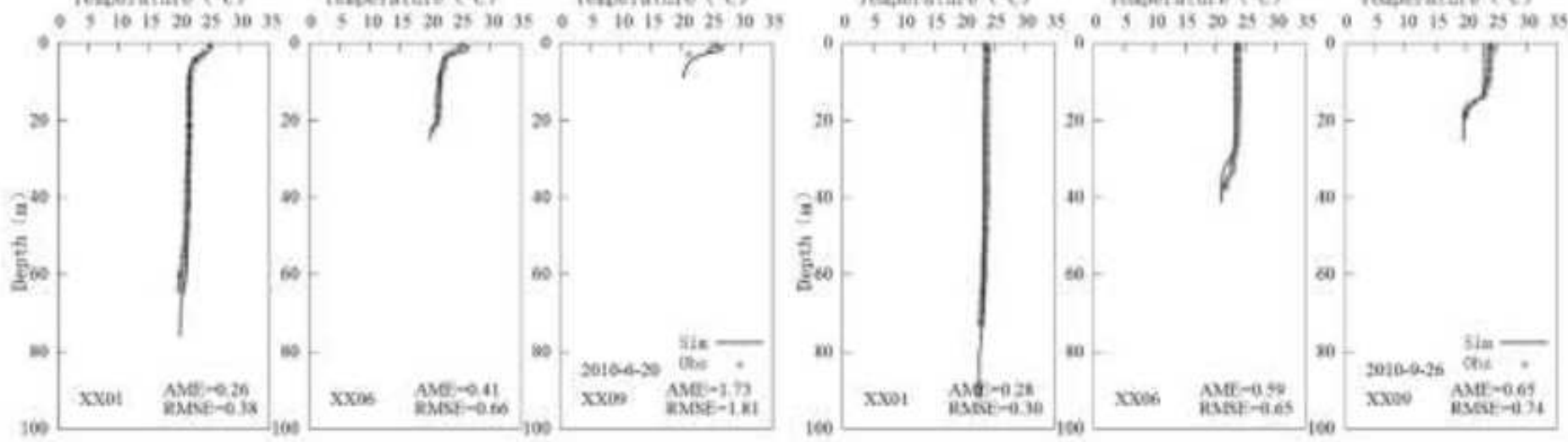

Figure 2

Temperature profile simulated (Sim) and observed (Obs) for XXB 


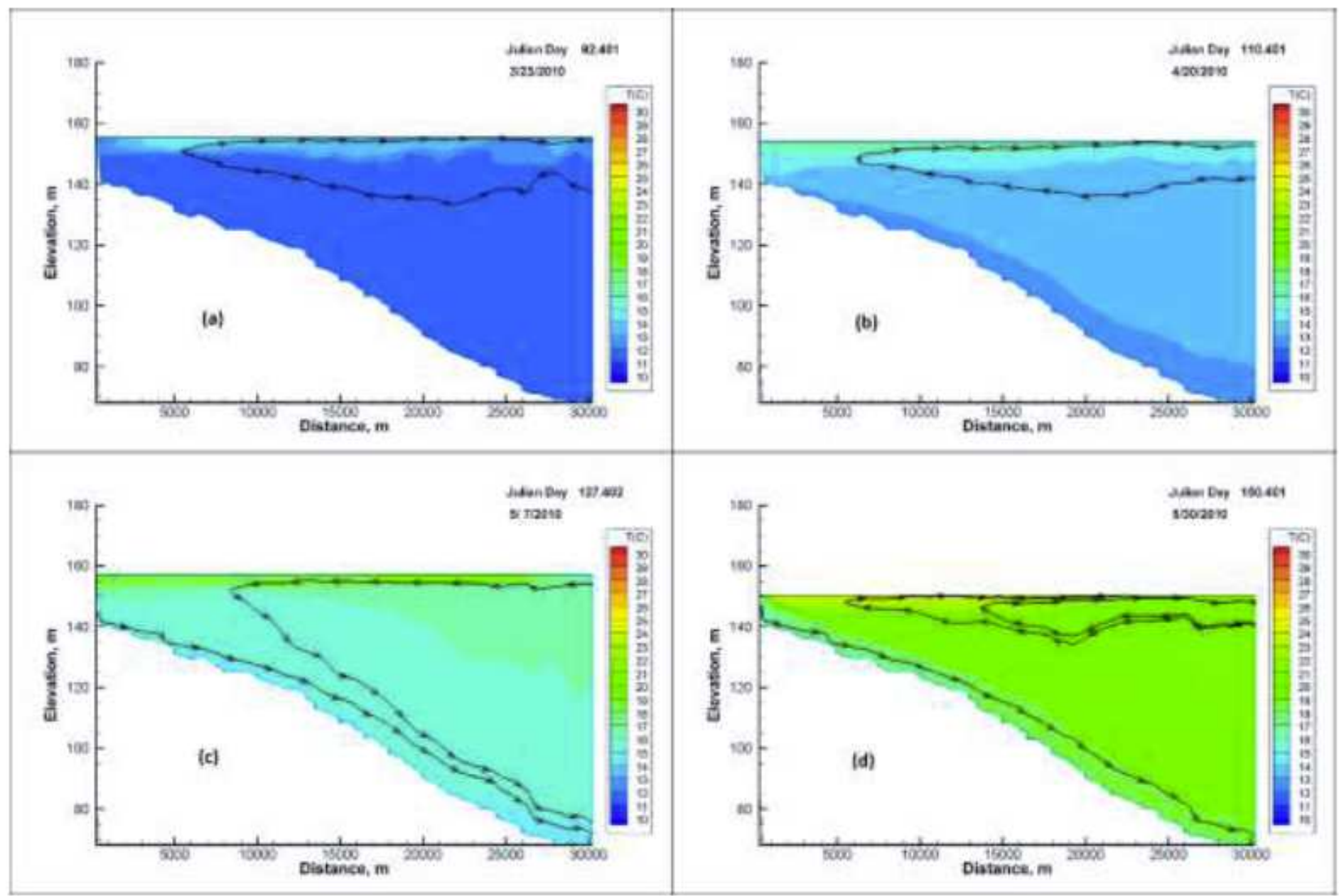

Figure 3

Contour plots represent overflow for XXB 


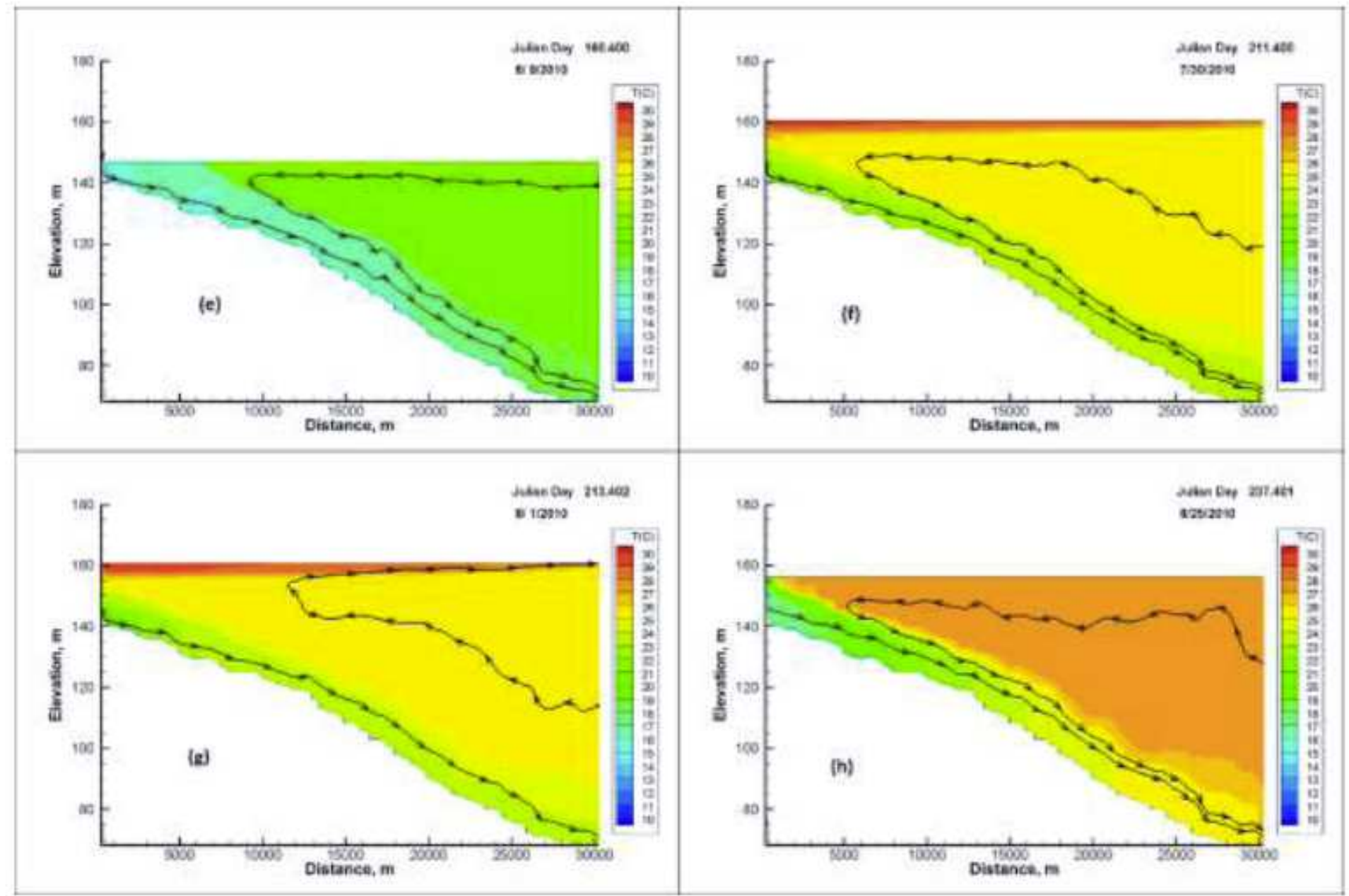

Figure 4

Contour plots represent interflow for XXB 


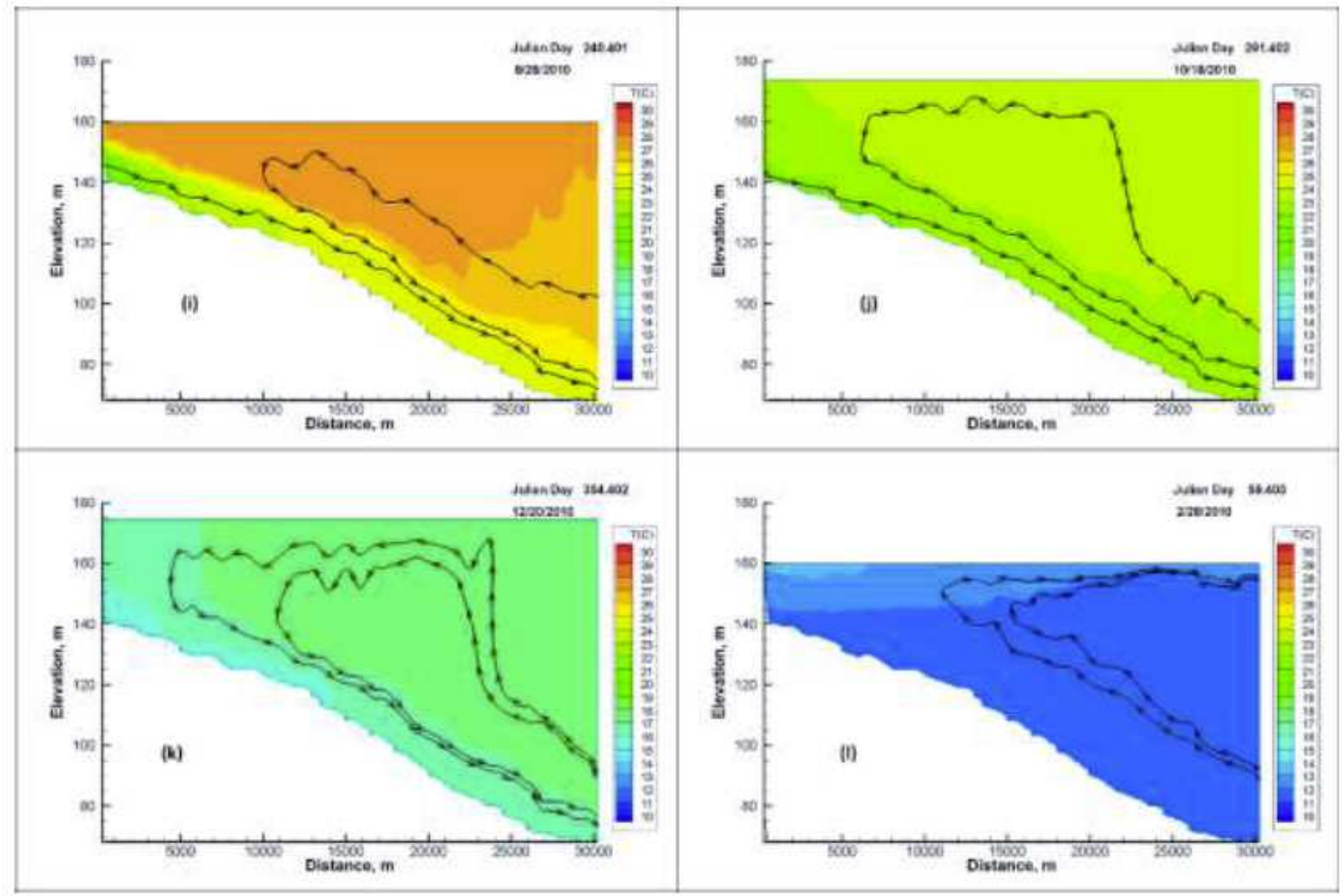

Figure 5

Contour plots represent underflow for XXB 